\title{
Measurement of Radioactivity of ${ }^{238} \mathrm{U},{ }^{226} \mathrm{Ra},{ }^{232} \mathrm{Th}$ and ${ }^{40} \mathrm{~K}$ in Soil of Different Geological Origins in Northern India
}

\author{
Rohit Mehra $^{1 *}$, Manmohan Singh ${ }^{2}$ \\ ${ }^{1}$ Department of Physics, Dr BR Ambedkar National Institute of Technology, Jalandhar, Punjab, India; ${ }^{2}$ Department of Physics, \\ Kanya Maha Vidyalaya, Jalandhar, Punjab, India. \\ Email: *rohit_mimit@rediffmail.com
}

Received March 21 ${ }^{\text {st }}, 2011$; revised July 19, 2011; accepted August 23 ${ }^{\text {rd }}, 2011$.

\begin{abstract}
Radioactivity of the nuclides ${ }^{238} \mathrm{U},{ }^{226} \mathrm{Ra},{ }^{232} \mathrm{Th}$ and ${ }^{40} \mathrm{~K}$ was measured in soil by $\gamma$-ray spectrometry using HPGe detector. A criterion was set in order to analyse soil samples from plain, semi-hilly and hilly areas in northern India. More than three $\gamma$-ray energy peaks were used for the determination of ${ }^{226} \mathrm{Ra}$ and ${ }^{232} \mathrm{Th}$ activity concentrations to obtain more accurate results. Some of these peaks have interfering energies, which was caused by the limited resolution of the detector, but they were resolved theoretically and used in the analysis because of their significance in reducing the random error to its minimum level. Relationships between the measured radionuclides have been discussed elaborately. Radionuclides ${ }^{238} U$ and ${ }^{226} R a$ were found in disequilibrium with ratio of specific activities $\left({ }^{238} U{ }^{226} R a\right)$ less than unity for most of the samples. In some cases this disequilibrium may be significant enough to modify the $\gamma$-ray dose factors.
\end{abstract}

Keywords: Soil, Natural Radionuclides, Disequilibrium, Dose

\section{Introduction}

There is a great interest all over the world in the study of terrestrial radioactivity to carry out the radiological characterisation of soils and building materials. This kind of study is important not only for the assessment of public dose rates and health risks but also to keep reference-data record to document the possible changes in the environmental radioactivity induced by humans in future as far as the nuclear activities are concerned [1].

Natural environmental radioactivity depends on the geological and geographic conditions, and appears at different levels in the soils of each different geological region [2]. It comes mainly from uranium $\left({ }^{238} \mathrm{U}\right)$ series, thorium $\left({ }^{232} \mathrm{Th}\right)$ series and natural potassium $\left({ }^{40} \mathrm{~K}\right)$. Abnormal occurrences of uranium and its decay products in rocks and soils, and thorium in monazite sands have been identified in several areas of the world, e.g., Yangjiang in China, Rasmar in Iran, Kerala coast of India, etc. [3-5].

This study deals with the measurement of specific activities of the naturally occurring radionuclides ${ }^{238} \mathrm{U}$, ${ }^{232} \mathrm{Th}$, and ${ }^{40} \mathrm{~K}$ ) in soil and consequently the assessment of $\gamma$-radiation dose. Soil samples were collected and their $\gamma$-radiation measured in our laboratory by $\gamma$-ray spec- trometry using HPGe detector. The samples were collected from four sites (Bathinda, Amritsar, Pathankot and Dalhousie). These sites cover different geographical features, especially sandy soil at Bathinda and rocks at Dalhousie, making them interesting sites for radiological studies. Each site is different geologically and as well as climatically from the other. Amritsar and Bathinda fall in plain area of Punjab state of India. Pathankot is semi-hilly area at the border of Punjab and Himachal Pradesh states. Dalhousie is situated in the mountains of Chamba district of Himachal Pradesh. Although Amritsar and Bathinda both are plain areas, the nature of soil at these places is quite different from each other. Soil at Amritsar mainly consists of silty clay of low to medium plasticity. Texture of the soil at Bathinda is sandy to silty. Majority of the soil at Pathankot is a mixture of pebbles and sandy loam. Soil at Dalhousie is formed of hard and compact sedimentary rock (silty sandstone). Rainfall is frequent in Dalhousie all over the year, while the climate is drier in Amritsar and Bathinda.

\section{Sample Collection and Measuring Methods}

Soil samples were collected from 24 points at selected 
four sites with 6 samples from each site. Each sample was taken from a depth of $5 \mathrm{~cm}-10 \mathrm{~cm}$ at a randomly chosen point within the site area. The only constraint was that no sample was taken close to a field boundary, tree, building, or other obstruction. However, sampling points at each site were selected at a minimum distance of $2 \mathrm{~km}$ from each other in order to cover a large area and to observe a significant local spatial variation in terrestrial radioactivity. In order to obtain representative samples, they were thoroughly mixed, sieved to remove stones, pebbles grass roots and straws and then crushed to pass through a 200 micron mesh sieve to homogenise the contents. Then they were air-dried for several days and finally, were packed in plastic cylindrical containers, which were well sealed with celluloid tape. The volume of the soil sample in the container was kept constant on $245 \mathrm{~cm}^{3}$. The samples filled in the containers were left for at least 4 weeks before measuring by $\gamma$-spectrometry in order to ensure that radioactive equilibrium was reached between ${ }^{226} \mathrm{Ra},{ }^{222} \mathrm{Rn}$, and hence ${ }^{222} \mathrm{Rn}$ progeny. The volume of the soil samples was equal to that of the standard sample to maintain the geometrical identity. Therefore, due to the varying density of soils, the sample weight was also varying.

Soil samples were analysed for the activity of natural radionuclides using a High Purity Germanium (HPGe) coaxial n-type detector at Inter University Accelerator Center(IUAC), New Delhi. The detector had a resolution of $2.0 \mathrm{KeV}$ at $1332 \mathrm{KeV}$ and relative efficiency of $20 \%$ relative to a 3" $\times 3$ " $\mathrm{NaI}(\mathrm{Tl})$ detector. Spectrum was analysed using the software "CANDLE" (Collection and Analysis of Nuclear Data using Linux Network)"developed locally at Inter University Accelerator Center. The detector was shielded using 4 " lead on all sides to reduce the background level of the system. Each sample was measured for a time period of 72,000 seconds. Activity concentration of each radionuclide was computed according to the following formula:

$$
\text { Activity }=\frac{\mathrm{PA} \times 100 \times 100}{\mathrm{I} \times \varepsilon \times 72000}
$$

where PA is peak area for a given energy, I is $\gamma$-ray intensity in percentage and $\varepsilon$ is efficiency in percentage of the detector for that energy.

It is well known that ${ }^{238} \mathrm{U}$ and ${ }^{226} \mathrm{Ra}$ may not be in secular equilibrium, therefore, an independent (from ${ }^{226} \mathrm{Ra}$ ) method was used to measure ${ }^{238} \mathrm{U}$.

\subsection{Estimation of ${ }^{238} \mathrm{U}$ Concentration}

Direct determination of ${ }^{238} U$ using semiconductor $\gamma$-ray spectrometer is very hard because ${ }^{238} \mathrm{U}$ does not have intensive $\gamma$-rays (lines) of its own. But it has several daughter products which have more intensive lines and activities equal to those of their parents in the state of secular equilibrium. The most intensive energies, used to determine ${ }^{238} \mathrm{U}$ contents, either come from ${ }^{226} \mathrm{Ra}$ and its progeny or from ${ }^{234} \mathrm{Th}[6]$. However, ${ }^{226} \mathrm{Ra}$ is generally not in equilibrium with ${ }^{238} \mathrm{U}$ because of geochemical reasons, therefore, the idea of using the energies of ${ }^{226} \mathrm{Ra}$ progeny was discarded. ${ }^{234} \mathrm{Th}$ is surely in equilibrium with ${ }^{238} \mathrm{U}$ and many authors use the $63.3 \mathrm{keV}(3.6 \%)$ and $92.6 \mathrm{keV}(4.9 \%)$ lines of ${ }^{234} \mathrm{Th}$ to determine ${ }^{238} \mathrm{U}$. However, the interference of the $92.6 \mathrm{keV}$ line from X-rays of $\mathrm{Bi}, \mathrm{Po}, \mathrm{U}$ and Th, and the interference of the $63.3 \mathrm{keV}$ line from a $63.7 \mathrm{keV}$ line of the thorium series may cause uncertainty in the results [7]. Moreover, the self absorption of these low-energy $\gamma$-rays in the sample material is significant and depends strongly on the varying composition and density of the sample. These facts may lead to the increase of the random error [8].

In the present study, ${ }^{238} \mathrm{U}$ was determined through the determination of ${ }^{235} \mathrm{U}$ assuming ${ }^{235} \mathrm{U} /{ }^{238} \mathrm{U}$ isotopic ratio to be constant for soils and rocks at $7.2 \times 10^{-3}$. ${ }^{235} \mathrm{U}$ is determined using its own intensive line at $185.7 \mathrm{keV}(57.5$ $\%)$. Intensity of this peak relative to ${ }^{238} \mathrm{U}$ is about $2.6 \%$ that gives a little bit lower peak intensity and higher statistical uncertainty than that of the $63.3 \mathrm{keV}$ peak of ${ }^{234} \mathrm{Th}$. However, the $185.7 \mathrm{keV}$ peak suffers from interference only from ${ }^{226} \mathrm{Ra}$, and the uncertainty caused by self-absorption is less because the higher $\gamma$-ray energy. The photo peak at the $185.7 \mathrm{keV}$ line is interfered by the $186.1 \mathrm{keV}$ line of ${ }^{226} \mathrm{Ra}$, which makes it necessary to resolve by using some mathematical relations. In the present analysis, the peak area under the $186 \mathrm{keV}$ peak, was treated as sum:

$$
\mathrm{PA}(186)=\mathrm{PA}\left({ }^{235} \mathrm{U}, 185.7\right)+\mathrm{PA}\left({ }^{226} \mathrm{Ra}, 186.1\right)
$$

To deduce ${ }^{226} \mathrm{Ra}$ contribution, it was assumed to be in equilibrium with its progeny. The intense $\gamma$-rays of ${ }^{214} \mathrm{~Pb}$ and ${ }^{214} \mathrm{Bi}$ were used subsequently to determine ${ }^{226} \mathrm{Ra}$ activity. For example, $295.2 \mathrm{keV} \gamma$-ray of ${ }^{214} \mathrm{~Pb}$ were chosen for this purpose to yield:

$$
\begin{aligned}
& \mathrm{PA}\left({ }^{226} \mathrm{Ra}, 186.1\right) \\
& =\frac{\varepsilon(186.1) \times \mathrm{I}\left({ }^{226} \mathrm{Ra}, 186.1\right)}{\varepsilon(295.2) \times \mathrm{I}\left({ }^{214} \mathrm{~Pb}, 295.2\right)} \times \mathrm{PA}\left({ }^{214} \mathrm{~Pb}, 295.2\right)
\end{aligned}
$$

where $\mathrm{I}\left({ }^{\mathrm{A}} \mathrm{X}, \mathrm{E}_{\gamma}\right)$ and $\varepsilon\left(\mathrm{E}_{\gamma}\right)$ are the emission probability and detection efficiency, respectively, for the $\mathrm{E}_{\gamma}(\mathrm{keV})$ $\gamma$-ray of radionuclide ${ }^{A} X$. Similarly, PA $\left({ }^{226} \mathrm{Ra}, 186.1\right)$ was computed also using the $351.9,609.3$ and $1120.3 \mathrm{keV}$ lines and the average value for $\mathrm{PA}\left({ }^{226} \mathrm{Ra}, 186.1\right)$ was computed and subtracted from the measured PA(186) to yield the value of $\mathrm{PA}\left({ }^{235} \mathrm{U}, 185.7\right)$ according to Equation (2). Activity of ${ }^{235} \mathrm{U}$ was, then, calculated using Equation (1). Finally, ${ }^{238} \mathrm{U}$ was computed from the following equa- 
tion:

$$
\begin{aligned}
& { }^{238} \mathrm{U}(\mathrm{Bq} / \mathrm{kg}) \\
& =\frac{\mathrm{T}_{1 / 2}\left({ }^{235} \mathrm{U}\right) \times \mathrm{M}\left({ }^{235} \mathrm{U}\right)}{\mathrm{T}_{1 / 2}\left({ }^{238} \mathrm{U}\right) \times \mathrm{M}\left({ }^{238} \mathrm{U}\right)} \times \frac{{ }^{235} \mathrm{U}(\mathrm{Bq} / \mathrm{kg})}{\mathrm{F}}
\end{aligned}
$$

where $\mathrm{T}_{1 / 2}\left({ }^{\mathrm{A}} \mathrm{X}\right)$ is the half-life and $\mathrm{M}\left({ }^{\mathrm{A}} \mathrm{X}\right)$ is atomic mass of radionuclide ${ }^{A} \mathrm{X}$. Factor $\mathrm{F}$ is ${ }^{235} \mathrm{U} /{ }^{238} \mathrm{U}$ isotopic, which is assumed to be constant for soil and rocks at $7.2 \times 10^{-3}$ [7].

\section{Results and Discussion}

\subsection{Specific Activities of ${ }^{238} \mathrm{U},{ }^{226} \mathrm{Ra},{ }^{232} \mathrm{Th}$ and ${ }^{40} \mathbf{K}$}

Table 1 illustrates the specific activities of the natural radionuclides $\left({ }^{238} \mathrm{U},{ }^{226} \mathrm{Ra},{ }^{232} \mathrm{Th}\right.$, and $\left.{ }^{40} \mathrm{~K}\right)$ in the samples collected from four sites. Activity of ${ }^{238} \mathrm{U}$, collectively for all the 24 soil samples, found to be ranged from 22.63 to $116.23 \mathrm{~Bq} / \mathrm{kg}$ with an average value of $50.5 \mathrm{~Bq} / \mathrm{kg}$. Activity of ${ }^{226} \mathrm{Ra}$ varied from 19.47 to $96.08 \mathrm{~Bq} / \mathrm{kg}$ with an average value of $54.13 \mathrm{~Bq} / \mathrm{kg}$. The ${ }^{232} \mathrm{Th}$ activity ranged from 30.2 to $136.12 \mathrm{~Bq} / \mathrm{kg}$ with an average value of $83.04 \mathrm{~Bq} / \mathrm{kg}$. While the activity of ${ }^{40} \mathrm{~K}$ ranged from 189.47 to $508.05 \mathrm{~Bq} / \mathrm{kg}$ with an average of $337.53 \mathrm{~Bq} / \mathrm{kg}$. Dalhousie location 3 has the highest values of ${ }^{238} \mathrm{U},{ }^{226} \mathrm{Ra}$ and ${ }^{232} \mathrm{Th}$, while Pathankot location 1 has the highest value of ${ }^{40} \mathrm{~K}$. Average activity concentrations of ${ }^{238} \mathrm{U}$, ${ }^{226} \mathrm{Ra}$ and ${ }^{232} \mathrm{Th}$ are significantly higher, and activity concentration of ${ }^{40} \mathrm{~K}$ is lower as compared to the worldwide average concentrations in soils of various countries, which are $33 \mathrm{~Bq} / \mathrm{kg}$ for ${ }^{238} \mathrm{U}, 32 \mathrm{~Bq} / \mathrm{kg}$ for ${ }^{226} \mathrm{Ra}, 45$ $\mathrm{Bq} / \mathrm{kg}$ for ${ }^{232} \mathrm{Th}$ and $420 \mathrm{~Bq} / \mathrm{kg}$ for ${ }^{40} \mathrm{~K}$ [2]. Each out of 24 soil samples follows the activity order as ${ }^{226} \mathrm{Ra}<{ }^{232} \mathrm{Th}$ $<{ }^{40} \mathrm{~K}$. For a detailed study, ${ }^{238} \mathrm{U} /{ }^{226} \mathrm{Ra},{ }^{232} \mathrm{Th} /{ }^{226} \mathrm{Ra}$, ${ }^{40} \mathrm{~K} /{ }^{226} \mathrm{Ra}$ and ${ }^{40} \mathrm{~K} /{ }^{232} \mathrm{Th}$ ratios are given in Table 2. It is generally expected that ${ }^{238} \mathrm{U}$ and ${ }^{226} \mathrm{Ra}$ being in the same series, are in equilibrium, however, diversity of their ratio from unity was found in the present measurements as explained separately in section $4.2 .{ }^{232} \mathrm{Th} /{ }^{226} \mathrm{Ra}$ varied in the range of 1.25 and 1.85 with an average value of 1.55. ${ }^{40} \mathrm{~K} /{ }^{226} \mathrm{Ra}$ ranged from 3.4 to 10.15 with an average value of $6.61 .{ }^{40} \mathrm{~K} /{ }^{232} \mathrm{Th}$ ranged from 2.72 to 6.54 with an average value of 4.27 . This ratio can be used as an indicator of the relative occurrence of these radionuclides. Studying each site individually, it can be seen from Table 1 that the average activity values of Bathinda samples are highest for ${ }^{238} \mathrm{U},{ }^{232} \mathrm{Th}$ and ${ }^{40} \mathrm{~K}$, while ${ }^{226} \mathrm{Ra}$ is highest for Dalhousie samples. The lowest average activity values of ${ }^{238} \mathrm{U},{ }^{226} \mathrm{Ra}$ and ${ }^{232} \mathrm{Th}$ are for Pathankot samples. Average activity of ${ }^{40} \mathrm{~K}$ is lowest for Amritsar samples. However, the contents of ${ }^{238} \mathrm{U}$ and ${ }^{232} \mathrm{Th}$ at Bathinda have insignificant difference from the corresponding contents at Dalhousie. Similarly, activity of ${ }^{226} \mathrm{Ra}$ at Bathinda is ap- proximately equal to that at Amritsar.

\subsection{Study of 238U/226Ra Activity Concentration Ratio}

Table 2 shows that 15 out of 24 samples have ${ }^{238} \mathrm{U} / 226 \mathrm{Ra}$ activity ratio less than unity. This ratio ranged from 0.56 to 1.56 having an average value of 0.95 . The average value of ${ }^{238} \mathrm{U}^{226} \mathrm{Ra}$ in UNSCEAR, 2000 report is about 1.03. However, after a detailed study of this report, it is found that most of the values of ${ }^{238} \mathrm{U}$ presented in the report are based on assuming ${ }^{238} \mathrm{U}$ and ${ }^{226} \mathrm{Ra}$ in equilibrium. Compiling only those ${ }^{238} \mathrm{U}$ values, which were measured independently by some means, it has been observed that 9 out of 17 countries have experienced ${ }^{238} \mathrm{U} /{ }^{226} \mathrm{Ra}$ activity ratio less than unity as can be seen in Table 3.

Navas et al. [9] have reported ${ }^{238} \mathrm{U} /{ }^{226} \mathrm{Ra}$ ratio as low as 0.55 in the upper layer of soils $(0 \mathrm{~cm}-20 \mathrm{~cm})$. They explained it by the significant differences in mobility of these radionuclides. According to them, ${ }^{238} \mathrm{U}$ may be intensively leached from the soil surface and transferred to deeper soil sections where it accumulates. In comparison ${ }^{226} \mathrm{Ra}$ is very immobile and keeps constant. This disturbance from equilibrium might be attributed to the weathering of rocks and the activity of water on the soil [6]. It is found that there is a positive correlation between ${ }^{238} \mathrm{U} /{ }^{226} \mathrm{Ra}$ ratio and water content in the soil [10]. Present study of ${ }^{238} \mathrm{U} /{ }^{226} \mathrm{Ra}$ provides further evidences for this fact as Dalhousie is known for frequent rain falling all over the year and average ${ }^{238} \mathrm{U} /{ }^{226} \mathrm{Ra}$ at this site is lowest to the value of 0.83 . On the other side, Amritsar and Bathinda have drier climate and exhibit higher ${ }^{238} \mathrm{U} /{ }^{226} \mathrm{Ra}$ ratio. More surprisingly Bathinda shows ${ }^{238} \mathrm{U}^{226} \mathrm{Ra}$ ratio more than unity. This may be attributed to the spread of fly ash enriched in uranium contents, which is originated from the combustion of coal from a thermal plant running in this area for more than 50 years.

\subsection{Dose Distribution of $\boldsymbol{\gamma}$-Radiations}

Distribution of ${ }^{226} \mathrm{Ra},{ }^{232} \mathrm{Th}$ and ${ }^{40} \mathrm{~K}$ in soil is not uniform. Therefore, in order to compare their combined radiological effect, a common index called the radium equivalent activity $\left(\mathrm{Ra}_{\mathrm{eq}}\right)$ was used. The radium equivalent activity is a weighted sum of activities of the above three radionuclides based on the assumption that 370 $\mathrm{Bq} / \mathrm{Kg}$ of ${ }^{226} \mathrm{Ra}, 259 \mathrm{~Bq} / \mathrm{Kg}$ of ${ }^{232} \mathrm{Th}$ and $4810 \mathrm{~Bq} / \mathrm{Kg}$ of ${ }^{40} \mathrm{~K}$ produces the same gamma dose rate. It is calculated through the following relation [11]:

$$
\mathrm{Ra}_{\mathrm{eq}}=370\left(\frac{\mathrm{C}_{\mathrm{Ra}}}{370}+\frac{\mathrm{C}_{\mathrm{Th}}}{259}+\frac{\mathrm{C}_{\mathrm{K}}}{4810}\right)
$$




$$
\mathrm{Ra}_{\mathrm{eq}}=\mathrm{C}_{\mathrm{Ra}}+1.43 \mathrm{C}_{\mathrm{Th}}+0.077_{\mathrm{K}}
$$

where $\mathrm{C}_{\mathrm{Ra}}, \mathrm{C}_{\mathrm{Th}}$ and $\mathrm{C}_{\mathrm{K}}$ are the activity concentrations (in $\mathrm{Bq} / \mathrm{kg}$ ) for ${ }^{226} \mathrm{Ra},{ }^{232} \mathrm{Th}$ and ${ }^{40} \mathrm{~K}$, respectively. It can be seen from Table 1 that the radium equivalent for all the 24 soil samples in the present study ranged between
$77.87 \mathrm{~Bq} / \mathrm{kg}$ for Pathankot location 6 and $325.71 \mathrm{~Bq} / \mathrm{kg}$ for Dalhousie location 3 at an average value of 198.86 $\mathrm{Bq} / \mathrm{kg}$, which is lower than the allowed maximum value of $370 \mathrm{~Bq} / \mathrm{kg}[11,12]$. The contributions of ${ }^{226} \mathrm{Ra},{ }^{232} \mathrm{Th}$ and ${ }^{40} \mathrm{~K}$ in the average value of $\mathrm{Ra}_{\mathrm{eq}}$ are in the ratio

Table 1. Activity concentration of ${ }^{238} \mathrm{U},{ }^{226} \mathrm{Ra},{ }^{232} \mathrm{Th}$, and ${ }^{40} \mathrm{~K}$ in some Indian soils (Bathinda, Amritsar, Pathankot and Dalhousie).

\begin{tabular}{|c|c|c|c|c|c|}
\hline Sample & $\begin{array}{c}{ }^{238} \mathrm{U} \\
(\mathrm{Bq} / \mathrm{kg})\end{array}$ & $\begin{array}{l}{ }^{226} \mathrm{Ra} \\
(\mathrm{Bq} / \mathrm{kg})\end{array}$ & $\begin{array}{l}{ }^{232} \mathrm{Th} \\
(\mathrm{Bq} / \mathrm{kg})\end{array}$ & $\begin{array}{c}{ }^{40} \mathrm{~K} \\
(\mathrm{~Bq} / \mathrm{kg})\end{array}$ & $\begin{array}{c}\mathrm{Ra}_{\mathrm{eq}} \\
(\mathrm{Bq} / \mathrm{kg})\end{array}$ \\
\hline Bathinda location 1 & $49.64 \pm 4.13$ & $57.16 \pm 1.08$ & $104.08 \pm 4.08$ & $489.55 \pm 5.15$ & $243.69 \pm 7.31$ \\
\hline Bathinda location 2 & $41.7 \pm 3.92$ & $44.12 \pm 0.88$ & $72.64 \pm 3.08$ & $252.75 \pm 3.10$ & $167.46 \pm 5.52$ \\
\hline Bathinda location 3 & $97.32 \pm 5.20$ & $82.28 \pm 1.48$ & $124.36 \pm 5.24$ & $507.5 \pm 5.53$ & $299.19 \pm 9.40$ \\
\hline Bathinda location 4 & $58.57 \pm 4.36$ & $74.68 \pm 1.24$ & $121.44 \pm 1.96$ & $486.45 \pm 5.28$ & $285.8 \pm 4.45$ \\
\hline Bathinda location 5 & $45.6 \pm 4.02$ & $41.88 \pm 0.80$ & $71.28 \pm 3.64$ & $272.28 \pm 3.28$ & $164.78 \pm 6.26$ \\
\hline Bathinda location 6 & $52.33 \pm 4.20$ & $33.92 \pm 0.56$ & $62.68 \pm 3.52$ & $253.73 \pm 3.10$ & $143.09 \pm 5.83$ \\
\hline Average & $57.53 \pm 4.30$ & $55.67 \pm 1.01$ & $92.75 \pm 3.59$ & $377.04 \pm 4.24$ & $217.33 \pm 6.46$ \\
\hline Standard deviation & 20.33 & 19.33 & 27.28 & 129.06 & 67.59 \\
\hline Amritsar location 1 & $35.26 \pm 3.73$ & $56.36 \pm 1.08$ & $90.64 \pm 3.28$ & $301.66 \pm 3.50$ & $209.20 \pm 6.04$ \\
\hline Amritsar location 2 & $31.40 \pm 3.61$ & $35.40 \pm 0.66$ & $49.72 \pm 1.71$ & $231.56 \pm 2.88$ & $124.33 \pm 3.33$ \\
\hline Amritsar location 3 & $55.47 \pm 4.28$ & $42.48 \pm 0.78$ & $65.48 \pm 2.91$ & $214.25 \pm 2.73$ & $152.61 \pm 5.15$ \\
\hline Amritsar location 4 & $37.81 \pm 3.80$ & $46.31 \pm 0.90$ & $57.73 \pm 2.46$ & $257.89 \pm 3.11$ & $148.72 \pm 4.66$ \\
\hline Amritsar location 5 & $40.27 \pm 3.87$ & $51.08 \pm 0.98$ & $74.10 \pm 3.67$ & $312.24 \pm 3.60$ & $181.09 \pm 6.51$ \\
\hline Amritsar location 6 & $103.46 \pm 5.31$ & $95.08 \pm 1.56$ & $132.16 \pm 5.12$ & $493.18 \pm 5.18$ & $322.04 \pm 9.28$ \\
\hline Average & $50.61 \pm 4.10$ & $54.45 \pm 0.99$ & $78.31 \pm 3.19$ & $301.80 \pm 3.50$ & $189.67 \pm 5.83$ \\
\hline Standard deviation & 27.17 & 21.16 & 29.92 & 101.25 & 71.13 \\
\hline Pathankot location 1 & $42.36 \pm 3.93$ & $56.96 \pm 1.04$ & $100.08 \pm 3.80$ & $508.05 \pm 5.32$ & $239.19 \pm 6.88$ \\
\hline Pathankot location 2 & $26.78 \pm 3.46$ & $20.38 \pm 0.47$ & $33.28 \pm 1.89$ & $189.47 \pm 2.52$ & $82.56 \pm 3.37$ \\
\hline Pathankot location 3 & $23.83 \pm 3.35$ & $34.72 \pm 0.72$ & $61.96 \pm 4.16$ & $242.08 \pm 3.00$ & $141.96 \pm 6.90$ \\
\hline Pathankot location 4 & $33.42 \pm 3.67$ & $59.32 \pm 1.11$ & $101.92 \pm 3.88$ & $442.5 \pm 4.78$ & $239.14 \pm 7.03$ \\
\hline Pathankot location 5 & $70.29 \pm 4.63$ & $64.30 \pm 1.14$ & $89.72 \pm 3.29$ & $403.39 \pm 4.41$ & $223.66 \pm 6.18$ \\
\hline Pathankot location 6 & $30.41 \pm 3.58$ & $19.47 \pm 0.51$ & $30.20 \pm 1.77$ & $197.6 \pm 2.56$ & $77.87 \pm 3.24$ \\
\hline Average & $37.85 \pm 3.77$ & $42.53 \pm 0.83$ & $69.53 \pm 3.13$ & $330.52 \pm 3.77$ & $167.40 \pm 5.60$ \\
\hline Standard deviation & 17.13 & 20.24 & 32.58 & 137.66 & 76.58 \\
\hline Dalhousie location 1 & $23.47 \pm 3.34$ & $29.26 \pm 0.55$ & $37.14 \pm 1.30$ & $223.78 \pm 2.82$ & $99.60 \pm 2.63$ \\
\hline Dalhousie location 2 & $74.86 \pm 4.73$ & $75.40 \pm 1.80$ & $126.72 \pm 5.40$ & $485.25 \pm 5.13$ & $293.97 \pm 9.92$ \\
\hline Dalhousie location 3 & $116.23 \pm 5.55$ & $96.08 \pm 1.68$ & $136.12 \pm 5.24$ & $454.28 \pm 4.88$ & $325.71 \pm 9.55$ \\
\hline Dalhousie location 4 & $22.63 \pm 3.31$ & $38.07 \pm 0.71$ & $51.56 \pm 2.23$ & $264.80 \pm 3.16$ & $132.19 \pm 4.14$ \\
\hline Dalhousie location 5 & $61.50 \pm 4.43$ & $87.44 \pm 1.44$ & $109.32 \pm 4.12$ & $297.10 \pm 3.47$ & $266.64 \pm 7.60$ \\
\hline Dalhousie location 6 & $37.43 \pm 3.79$ & $57.00 \pm 0.96$ & $88.52 \pm 3.59$ & $319.48 \pm 3.60$ & $208.18 \pm 6.37$ \\
\hline Average & $56.02 \pm 4.19$ & $63.88 \pm 1.19$ & $91.56 \pm 3.65$ & $340.78 \pm 3.84$ & $221.05 \pm 6.70$ \\
\hline Standard deviation & 36.14 & 26.97 & 40.27 & 105.43 & 90.73 \\
\hline
\end{tabular}


Table 2. Activity concentration ratios ${ }^{238} \mathrm{U} /{ }^{226} \mathrm{Ra},{ }^{232} \mathrm{Th} /{ }^{226} \mathrm{Ra},{ }^{40} \mathrm{~K} /{ }^{226} \mathrm{Ra}$ and ${ }^{40} \mathrm{~K} /{ }^{232} \mathrm{Th}$ in some Indian soils (Bathinda, Amritsar, Pathankot and Dalhousie).

\begin{tabular}{|c|c|c|c|c|}
\hline Sample & ${ }^{238} \mathrm{U} /{ }^{226} \mathrm{Ra}$ & ${ }^{232} \mathrm{Th} /{ }^{226} \mathrm{Ra}$ & ${ }^{40} \mathrm{~K} /{ }^{226} \mathrm{Ra}$ & ${ }^{40} \mathrm{~K} /{ }^{232} \mathrm{Th}$ \\
\hline Bathinda location 1 & $0.87 \pm 0.09$ & $1.82 \pm 0.11$ & $8.56 \pm 0.25$ & $4.70 \pm 0.23$ \\
\hline Bathinda location 2 & $0.95 \pm 0.11$ & $1.65 \pm 0.10$ & $5.73 \pm 0.18$ & $3.48 \pm 0.19$ \\
\hline Bathinda location 3 & $1.18 \pm 0.08$ & $1.51 \pm 0.09$ & $6.17 \pm 0.18$ & $4.08 \pm 0.22$ \\
\hline Bathinda location 4 & $0.78 \pm 0.07$ & $1.63 \pm 0.05$ & $6.51 \pm 0.18$ & $4.01 \pm 0.11$ \\
\hline Bathinda location 5 & $1.09 \pm 0.12$ & $1.70 \pm 0.12$ & $6.50 \pm 0.20$ & $3.82 \pm 0.24$ \\
\hline Bathinda location 6 & $1.54 \pm 0.15$ & $1.85 \pm 0.13$ & $7.48 \pm 0.21$ & $4.05 \pm 0.28$ \\
\hline Average & $1.07 \pm 0.10$ & $1.69 \pm 0.10$ & $6.83 \pm 0.20$ & $4.02 \pm 0.21$ \\
\hline Standard deviation & 0.27 & 0.13 & 1.03 & 0.40 \\
\hline Amritsar location 1 & $0.63 \pm 0.08$ & $1.61 \pm 0.09$ & $5.35 \pm 0.16$ & $3.33 \pm 0.16$ \\
\hline Amritsar location 2 & $0.89 \pm 0.12$ & $1.40 \pm 0.07$ & $6.54 \pm 0.20$ & $4.66 \pm 0.22$ \\
\hline Amritsar location 3 & $1.31 \pm 0.12$ & $1.54 \pm 0.10$ & $5.04 \pm 0.16$ & $3.27 \pm 0.19$ \\
\hline Amritsar location 4 & $0.82 \pm 0.10$ & $1.25 \pm 0.08$ & $5.57 \pm 0.18$ & $4.47 \pm 0.24$ \\
\hline Amritsar location 5 & $0.79 \pm 0.09$ & $1.45 \pm 0.10$ & $6.11 \pm 0.19$ & $4.21 \pm 0.26$ \\
\hline Amritsar location 6 & $1.09 \pm 0.07$ & $1.39 \pm 0.08$ & $5.19 \pm 0.14$ & $3.73 \pm 0.18$ \\
\hline Average & $0.92 \pm 0.10$ & $1.44 \pm 0.09$ & $5.63 \pm 0.17$ & $3.95 \pm 0.21$ \\
\hline Standard deviation & 0.24 & 0.13 & 0.58 & 0.59 \\
\hline Pathankot location 1 & $0.74 \pm 0.08$ & $1.76 \pm 0.10$ & $8.92 \pm 0.26$ & $5.08 \pm 0.25$ \\
\hline Pathankot location 2 & $1.31 \pm 0.20$ & $1.63 \pm 0.13$ & $9.30 \pm 0.34$ & $5.69 \pm 0.40$ \\
\hline Pathankot location 3 & $0.69 \pm 0.11$ & $1.78 \pm 0.16$ & $6.97 \pm 0.23$ & $3.91 \pm 0.31$ \\
\hline Pathankot location 4 & $0.56 \pm 0.07$ & $1.72 \pm 0.10$ & $7.46 \pm 0.22$ & $4.34 \pm 0.21$ \\
\hline Pathankot location 5 & $1.09 \pm 0.09$ & $1.40 \pm 0.08$ & $6.27 \pm 0.18$ & $4.50 \pm 0.21$ \\
\hline Pathankot location 6 & $1.56 \pm 0.22$ & $1.55 \pm 0.13$ & $10.15 \pm 0.40$ & $6.54 \pm 0.47$ \\
\hline Average & $0.99 \pm 0.13$ & $1.64 \pm 0.12$ & $8.18 \pm 0.27$ & $5.01 \pm 0.31$ \\
\hline Standard deviation & 0.39 & 0.15 & 1.50 & 0.97 \\
\hline Dalhousie location 1 & $0.80 \pm 0.13$ & $1.27 \pm 0.07$ & $7.65 \pm 0.24$ & $6.03 \pm 0.29$ \\
\hline Dalhousie location 2 & $0.99 \pm 0.09$ & $1.68 \pm 0.11$ & $6.44 \pm 0.22$ & $3.83 \pm 0.20$ \\
\hline Dalhousie location 3 & $1.21 \pm 0.08$ & $1.42 \pm 0.08$ & $4.73 \pm 0.13$ & $3.34 \pm 0.16$ \\
\hline Dalhousie location 4 & $0.59 \pm 0.10$ & $1.35 \pm 0.08$ & $6.96 \pm 0.21$ & $5.14 \pm 0.28$ \\
\hline Dalhousie location 5 & $0.70 \pm 0.06$ & $1.25 \pm 0.07$ & $3.40 \pm 0.10$ & $2.72 \pm 0.13$ \\
\hline Dalhousie location 6 & $0.66 \pm 0.08$ & $1.55 \pm 0.09$ & $5.60 \pm 0.16$ & $3.61 \pm 0.19$ \\
\hline Average & $0.83 \pm 0.09$ & $1.42 \pm 0.08$ & $5.80 \pm 0.18$ & $4.11 \pm 0.21$ \\
\hline Standard deviation & 0.23 & 0.17 & 1.56 & 1.23 \\
\hline
\end{tabular}

Table 3. Activity concentration ratio ${ }^{238} \mathrm{U} /{ }^{226} \mathrm{Ra}$ in various countries (UNSCEAR, 2000).

\begin{tabular}{lc}
\hline Country & ${ }^{238} \mathrm{U}\left(\mathrm{Bq} \mathrm{m}^{-3}\right) /{ }^{226} \mathrm{Ra}\left(\mathrm{Bq} \mathrm{m}^{-3}\right)$ \\
\hline Algeria & $30 / 50(0.60)$ \\
Egypt & $37 / 17(2.18)$ \\
United States & $35 / 40(0.88)$ \\
China & $33 / 32(1.03)$ \\
Hong Kong & $84 / 59(1.42)$ \\
Japan & $29 / 33(0.88)$ \\
Kazakhstan & $37 / 35(1.06)$ \\
Malaysia & $66 / 67(0.99)$ \\
Thailand & $114 / 48(2.38)$ \\
Armenia & $46 / 51(0.90)$ \\
Syrian Arab Republic & $23 / 20(1.15)$ \\
Ireland & $37 / 60(0.62)$ \\
Bulgaria & $40 / 45(0.89)$ \\
Hungary & $29 / 33(0.88)$ \\
Russian Federation & $19 / 27(0.70)$ \\
Croatia & $110 / 54(2.04)$ \\
Portugal & $49 / 44(1.11)$ \\
\hline
\end{tabular}


27.2:59.7:13.1. Average results of $\mathrm{Ra}_{\mathrm{eq}}$ for each site are also listed in Table 1, which is highest at Dalhousie at the value of $221.05 \mathrm{~Bq} / \mathrm{kg}$ and lowest at Pathankot at the value of $167.4 \mathrm{~Bq} / \mathrm{kg}$.

The external terrestrial $\gamma$-radiation absorbed dose rate in air at a height of about $1 \mathrm{~m}$ above the ground is calculated by using the following relation [2]:

$$
\mathrm{D}(\mathrm{nGy} / \mathrm{h})=0.462 \mathrm{C}_{\mathrm{Ra}}+0.604 \mathrm{C}_{\mathrm{Th}}+0.0417 \mathrm{C}_{\mathrm{K}}
$$

Results of $\gamma$-radiation absorbed dose rate are shown in Table 4. It ranged between $35.48 \mathrm{nGy} / \mathrm{h}$ for Pathankot location 6 and $145.55 \mathrm{nGy} / \mathrm{h}$ for Dalhousie location 3 at an average value of $89.24 \mathrm{nGy} / \mathrm{h}$, which is higher by a factor of 1.49 than the world's average value of $60 \mathrm{nGy} / \mathrm{h}$ [2].The contributions of ${ }^{226} \mathrm{Ra},{ }^{232} \mathrm{Th}$ and ${ }^{40} \mathrm{~K}$ in the average value are in the ratio 28:56.2:15.78. Results for each sample as well as average results for each site are also listed in Table 4.

To estimate annual effective dose, account was taken of the conversion coefficient from absorbed dose in air to effective dose and the indoor occupancy factor. The committee used $0.7 \mathrm{~Sv} / \mathrm{Gy}$ for the conversion coefficient from absorbed dose in air to effective dose received by adults, and 0.2 for the outdoor occupancy factor $[2,13]$. Effective dose rate outdoors in units of $\mathrm{mSv}$ per year was calculated by the following formula:

Annual effective dose $(\mathrm{mSv})$

$$
=\mathrm{D}(\mathrm{nGy} / \mathrm{h}) \times 8,760 \mathrm{~h} \times 0.2 \times 0.7 \mathrm{~Sv} / \mathrm{Gy} \times 10^{-6}
$$

Results for outdoor annual effective dose are shown in Table 4. It ranged from 0.4 to $0.18 \mathrm{mSv}$ with an average

Table 4. Absorbed dose rates from ${ }^{226} \mathrm{Ra},{ }^{232} \mathrm{Th}$, and ${ }^{40} \mathrm{~K}$ and annual effective dose (Bathinda, Amritsar, Pathankot and Dal-

\begin{tabular}{|c|c|c|c|c|c|}
\hline \multirow[b]{2}{*}{ Sample } & \multicolumn{4}{|c|}{ Absorbed dose rate } & \multirow[b]{2}{*}{$\begin{array}{l}\text { Annual effective dose } \\
\text { (mSv) }\end{array}$} \\
\hline & $\begin{array}{l}{ }^{226} \mathrm{Ra} \\
(\mathrm{nGy} / \mathrm{h})\end{array}$ & $\begin{array}{l}{ }^{232} \mathrm{Th} \\
(\mathrm{nGy} / \mathrm{h})\end{array}$ & $\begin{array}{c}{ }^{40} \mathrm{~K} \\
(\mathrm{nGy} / \mathrm{h})\end{array}$ & $\begin{array}{c}\text { Total } \\
\text { (nGy/h) }\end{array}$ & \\
\hline Bathinda location 1 & $26.41 \pm 0.50$ & $62.86 \pm 2.46$ & $20.41 \pm 0.21$ & $109.69 \pm 3.18$ & $0.135 \pm 0.004$ \\
\hline Bathinda location 2 & $20.38 \pm 0.41$ & $43.87 \pm 1.86$ & $10.54 \pm 0.13$ & $74.80 \pm 2.39$ & $0.092 \pm 0.003$ \\
\hline Bathinda location 3 & $38.01 \pm 0.68$ & $75.11 \pm 3.16$ & $21.16 \pm 0.23$ & $134.29 \pm 4.08$ & $0.165 \pm 0.005$ \\
\hline Bathinda location 4 & $34.50 \pm 0.57$ & $73.35 \pm 1.18$ & $20.28 \pm 0.22$ & $128.14 \pm 1.97$ & $0.157 \pm 0.002$ \\
\hline Bathinda location 5 & $19.35 \pm 0.37$ & $43.05 \pm 2.20$ & $11.35 \pm 0.14$ & $73.76 \pm 2.70$ & $0.090 \pm 0.003$ \\
\hline Bathinda location 6 & $15.67 \pm 0.26$ & $37.86 \pm 2.13$ & $10.58 \pm 0.13$ & $64.11 \pm 2.51$ & $0.079 \pm 0.003$ \\
\hline Average & $25.72 \pm 0.47$ & $56.02 \pm 2.17$ & $15.72 \pm 0.18$ & $97.47 \pm 2.81$ & $0.120 \pm 0.003$ \\
\hline Standard deviation & 8.93 & 16.48 & 5.38 & 30.45 & 0.037 \\
\hline Amritsar location 1 & $26.04 \pm 0.50$ & $54.75 \pm 1.98$ & $12.58 \pm 0.15$ & $93.36 \pm 2.63$ & $0.114 \pm 0.003$ \\
\hline Amritsar location 2 & $16.35 \pm 0.30$ & $30.03 \pm 1.03$ & $9.66 \pm 0.12$ & $56.04 \pm 1.46$ & $0.069 \pm 0.002$ \\
\hline Amritsar location 3 & $19.63 \pm 0.36$ & $39.55 \pm 1.76$ & $8.93 \pm 0.11$ & $68.11 \pm 2.23$ & $0.084 \pm 0.003$ \\
\hline Amritsar location 4 & $21.40 \pm 0.42$ & $34.87 \pm 1.49$ & $10.75 \pm 0.13$ & $67.02 \pm 2.03$ & $0.082 \pm 0.002$ \\
\hline Amritsar location 5 & $23.60 \pm 0.45$ & $44.76 \pm 2.22$ & $13.02 \pm 0.15$ & $81.38 \pm 2.84$ & $0.100 \pm 0.003$ \\
\hline Amritsar location 6 & $43.93 \pm 0.72$ & $79.82 \pm 3.09$ & $20.57 \pm 0.22$ & $144.32 \pm 4.03$ & $0.177 \pm 0.005$ \\
\hline Average & $25.16 \pm 0.46$ & $47.30 \pm 1.93$ & $12.59 \pm 0.15$ & $85.04 \pm 2.53$ & $0.104 \pm 0.003$ \\
\hline Standard deviation & 9.78 & 18.07 & 4.22 & 31.78 & 0.039 \\
\hline Pathankot location 1 & $26.32 \pm 0.48$ & $60.45 \pm 2.30$ & $21.19 \pm 0.22$ & $107.95 \pm 3.00$ & $0.132 \pm 0.004$ \\
\hline Pathankot location 2 & $9.42 \pm 0.22$ & $20.10 \pm 1.14$ & $7.90 \pm 0.11$ & $37.42 \pm 1.46$ & $0.046 \pm 0.002$ \\
\hline Pathankot location 3 & $16.04 \pm 0.33$ & $37.42 \pm 2.51$ & $10.09 \pm 0.13$ & $63.56 \pm 2.97$ & $0.078 \pm 0.004$ \\
\hline Pathankot location 4 & $27.41 \pm 0.51$ & $61.56 \pm 2.34$ & $18.45 \pm 0.20$ & $107.42 \pm 3.06$ & $0.132 \pm 0.004$ \\
\hline Pathankot location 5 & $29.71 \pm 0.53$ & $54.19 \pm 1.99$ & $16.82 \pm 0.18$ & $100.72 \pm 2.70$ & $0.124 \pm 0.003$ \\
\hline Pathankot location 6 & $9.00 \pm 0.24$ & $18.24 \pm 1.07$ & $8.24 \pm 0.11$ & $35.48 \pm 1.41$ & $0.044 \pm 0.002$ \\
\hline Average & $19.65 \pm 0.38$ & $41.99 \pm 1.89$ & $13.78 \pm 0.16$ & $75.43 \pm 2.43$ & $0.093 \pm 0.003$ \\
\hline Standard deviation & 9.35 & 19.68 & 5.74 & 34.36 & 0.042 \\
\hline Dalhousie location 1 & $13.52 \pm 0.25$ & $22.43 \pm 0.79$ & $9.33 \pm 0.12$ & $45.28 \pm 1.16$ & $0.056 \pm 0.001$ \\
\hline Dalhousie location 2 & $34.83 \pm 0.83$ & $76.54 \pm 3.26$ & $20.23 \pm 0.21$ & $131.61 \pm 4.31$ & $0.161 \pm 0.005$ \\
\hline Dalhousie location 3 & $44.39 \pm 0.78$ & $82.22 \pm 3.16$ & $18.94 \pm 0.20$ & $145.55 \pm 4.14$ & $0.179 \pm 0.005$ \\
\hline Dalhousie location 4 & $17.59 \pm 0.33$ & $31.14 \pm 1.35$ & $11.04 \pm 0.13$ & $59.77 \pm 1.81$ & $0.073 \pm 0.002$ \\
\hline Dalhousie location 5 & $40.40 \pm 0.67$ & $66.03 \pm 2.49$ & $12.39 \pm 0.14$ & $118.82 \pm 3.30$ & $0.146 \pm 0.004$ \\
\hline Dalhousie location 6 & $26.33 \pm 0.44$ & $53.47 \pm 2.17$ & $13.32 \pm 0.15$ & $93.12 \pm 2.76$ & $0.114 \pm 0.003$ \\
\hline Average & $29.51 \pm 0.55$ & $55.31 \pm 2.20$ & $14.21 \pm 0.16$ & $99.03 \pm 2.91$ & $0.121 \pm 0.004$ \\
\hline Standard deviation & 12.46 & 24.32 & 4.40 & 40.21 & 0.049 \\
\hline
\end{tabular}
housie). 
value of $0.11 \mathrm{mSv}$, while the world wide outdoor average annual effective dose is approximately $0.07 \mathrm{mSv}$ [2]. Only three samples, Pathankot location 2, Pathankot location 6 and Dalhousie location 1, have lower values than the worldwide average value, which are $0.05,0.04$ and $0.06 \mathrm{mSv}$, respectively. Average annual effective doses at Bathinda and Dalhousie are equal at $0.12 \mathrm{mSv}$ and are higher than other two sites Amritsar by factor of 1.20 and Pathankot by a factor of 1.33 .

\section{Conclusions}

1) For the determination of ${ }^{226} \mathrm{Ra}$ and ${ }^{232} \mathrm{Th}$ activity concentrations, more than three $\gamma$-ray energy peaks were used.

2) Average activity concentrations of ${ }^{238} \mathrm{U},{ }^{226} \mathrm{Ra}$ and ${ }^{232} \mathrm{Th}$ are higher and activity concentration of ${ }^{40} \mathrm{~K}$ is lower as compared to the worldwide average concentration.

3) Dalhousie exhibit lowest ${ }^{238} \mathrm{U}^{226} \mathrm{Ra}$ ratio while Amritsar and Bathinda exhibit higher ${ }^{238} \mathrm{U} /{ }^{226} \mathrm{Ra}$ ratio due to their different climatic changes.

Average results of $\mathrm{Ra}_{\mathrm{eq}}$ is highest at Dalhousie with value $221.05 \mathrm{~Bq} / \mathrm{kg}$ and lowest at Pathankot with value $167.4 \mathrm{~Bq} / \mathrm{kg}$.

\section{REFERENCES}

[1] M. Tufail, N. Akhtar and N. Waqas, "Measurement of Terrestrial Radiation for Assessment of Gamma Dose from Cultivated and Barren Saline Soils of Faisalabad of Pakistan," Radiation Measurement, Vol. 41, No. 4, 2006, pp. 443-451. doi:10.1016/j.radmeas.2005.10.007

[2] UNSCEAR, "United Nations Scientific Committee on the Effects of Atomic Radiation. Sources and Effects of Ionizing Radiations," United Nations, New York, 2000.

[3] M. Sohrabi, "Recent Radiological Studies of High Level Natural Radiation Areas of Rasmar," Proceeding of the International Conference on High Levels of Natural Radiation, Rasmar, IAEA, Vienna, 1993.

[4] C. M. Sunta, "A Review of the Studies of High Background Areas of the S-W Coast of India," Proceeding of the International Conference on High Levels of Natural Radiation, Rasmar, IAEA, Vienna, 1993.
[5] H. Zhu, H. Huang, J. Song, J. Li, J. Zhang, J. Huang, Y. Zha and Y. Guo, "Gamma Radiation Levels Around the Highest Background Area in Poland," Proceeding of the International Conference on High Levels of Natural Radiation, Rasmar, IAEA, Vienna, 1993.

[6] M. J. Anagnostakis, E. P. Hinis, D. J. Karangelos, N. P. Petropoulos, P. K. Rouni, S. E. Simopoulos and Z. S. Zunic, "Determination of Depleted Uranium in Environmental Samples by Gamma-Spectroscopic Techniques," Archive of Oncology, Vol. 9, 2001, pp. 231-236.

[7] A. S. Murray and M. J. Aitken, "Analysis of Low-Level Natural Radioactivity in Small Mineral Samples for Use in Thermoluminescence Dating, Using High Resolution Gamma Spectrometry," Applied Radiation and Isotopes, Vol. 39, No. 2, 1988, pp. 145-158. doi:10.1016/0883-2889(88)90160-8

[8] Z. Papp, Z. Dezso and S. Daroczy, "Measurement of the Radioactivity of ${ }^{238} \mathrm{U},{ }^{232} \mathrm{Th},{ }^{226} \mathrm{Ra},{ }^{137} \mathrm{Cs}$ and ${ }^{40} \mathrm{~K}$ in Soil Using Direct Ge(Li) $\gamma$-Ray Spectrometry," Journal of Radioanalytical and Nuclear Chemistry, Vol. 222, No. 1-2, 1997, pp. 171-176. doi:10.1007/BF02034265

[9] A. Navas, J .Soto and J. Machin, ${ }^{6238} \mathrm{U},{ }^{226} \mathrm{Ra},{ }^{210} \mathrm{~Pb},{ }^{232} \mathrm{Th}$ and ${ }^{40} \mathrm{~K}$ Activities in Soil Profiles of the Flysch Sector (Central Spanish Pyrenees)," Applied Radiation and Isotopes, Vol. 57, No. 4, 2002, pp. 579-589. doi:10.1016/S0969-8043(02)00131-8

[10] M. Dowdall and J. O'Dea, ${ }^{6226} \mathrm{Ra} /{ }^{238} \mathrm{U}$ Disequilibrium in an Upland Organic Soil Exhibiting Elevated Natural Radioactivity," Journal of Environmental Radioactivity, Vol. 59, No. 1, 2002, pp. 91-104. doi:10.1016/S0265-931X(01)00038-8

[11] J. Beretka and P.J. Mathew, "Natural Radioactivity of Australian Building Materials, Industrial Wastes and by-Products," Health Physics, Vol. 48, No. 1, 1985, pp. 87-95. doi:10.1097/00004032-198501000-00007

[12] OECD, "Exposure to Radiation from the Natural Radioactivity in Building Materials," Report by a Group of Experts of the OECD, Nuclear Energy Agency, Paris, 1979.

[13] UNSCEAR, "United Nations Scientific Committee on the Effects of Atomic Radiation. Ionizing Radiation Sources and Biological Effects," Reports to general assembly, United Nations, New York, 1993. 